\title{
生态环保理念的生态公路设计探索
}

张新路

内蒙古兴安盟公路管理局第九公路养护管理工区

DOI:10.32629/eep.v1i3.46

[摘 要] 随着经济的发展、科学技术的日新月异,我国的国际地位也在不断提升。城市化进程的不断推进证实了这一事实。 城市越来越拥挤, 所以越来越多的道路依赖于技术, 但目前存在一个问题。经济发展虽然重要,但生态环境也很重要。由于整个 城市发展较早,道路周边生态环境恶化,部分城市受到严重破坏。本文分析了基于环境保护理念的生态公路相关内容进行研究。 [关键词] 环保理念; 公路设计; 生态公路

\section{1 基于生态环保的公路设计理念}

\section{1 环境保护设计理念}

公路的设计都需要对其所影响到的周边环境进行妥善 处置, 使得这种环境冲突达到最小。首先, 一般的公路周边环 境, 应该以尽可能少占据用地及减少工程开挖为基本原则, 保护建设环境的地形和地貌, 而如果公路建设中造成了一定 的破坏, 则需要进行适当的恢复乃至加固设计。其次, 对于具 有人文景观的建设环境, 公路的设计一方面可以开发人文景 观作为旅游资源, 通过公路建设带动区域交通与经济发展, 另一方面也需要尽可能降低对这些人文景观的影响, 不能直 接从人文景观区域通行, 而需要采取绕行设计方法。环境保 护的原则是使得设计建造后的公路与周边环境达到协调。

\section{2 绿色节能设计理念}

生态环保的一个重要方面就是绿色节能, 现如今各种绿 色节能技术得到应用, 可以在施工工艺上降低对环境的污染, 减少施工扬尘同时使得结构的运营保持绿色安全性。绿色节 能技术往往在建设初期投入较大, 而从全寿命成本的角度进 行考虑, 其全寿命成本是优化的。所采用的绿色节能技术可 以是节能环保材料, 或者是新型节能技术等。

\section{2 环保公路的现状}

2.1 生态公路的要素

生态环境与高速公路的结合其实就是狭义生态道路的 意义。广阔的生态道路实际上不仅仅是这些简单的绿色植物, 生态包括路边。实用的便利人们生活的设施, 如栅栏, 垃圾桶, 立交桥和地下通道。艺术景观, 如喷泉, 雕塑, 花坛等与绿色 植物具有同等美化效果; 宣传效果的海报, 路标和其他标志。 此外, 生态包括道路两侧的建筑物, 如上海的东方明珠, 哈尔 滨的圣索菲亚教堂, 乌鲁木齐的国际集市……这些建筑物四 处可见。综上所述, 生态公共元素包括道路, 大型建筑物, 小 型广告牌, 花草木等所有环境。

\section{2 生态公路的重要性}

从名称上可以看到生态高速公路与自然环境之间有着 密不可分的联系, 生态起着美化的作用。这是生态道路最基 本的作用。随着全球气候变暖, 环境保护问题越来越受到关 注, 环境保护的核心是生态。所有的树都是地球的肺部, 这足
以看到绿色植被的重要性, 城市道路两侧的自然生态也在炎 热的夏季起到遮蔽效应, 缓解噪音污染。生态道路归根结底, 它包含着绿色植被, 因此它也在调节地球生态平衡方面发挥 着重要作用。另外, 生态道路上的植被也是一条保护行人安 全的独立道路。道路的作用不多说, 但植被如何保护行人的 安全这是因为植被通常是空隙, 并不能完全阻挡行人的视 线。所以它只起到一定的屏蔽作用。生态道路不仅美化了自 然环境, 更重要的是在便捷交通的同时保护了自然生态。

\section{3 生态公路建设存在的问题}

目前, 基于环境保护理念的生态道路建设存在诸多问题, 其中最重要的问题是意识问题。相关人士对生态公路建设不 够重视, 建设者不会看重生态环境。目前, 生态公路建设存在 四个问题。来源问题: 重度缺乏知名度; 设计问题: 道路设 计不具创意并且没有眼球。执行问题: 在施工中, 不考虑地 理位置, 一些天然植被正在燃烧之下。在天然气管道或污水 管道中, 植被不能在一定阶段吸收养分, 最终不能得到营养 而死亡; 维护问题: 认为生态环境保护不够, 没有规律合理 的浇筑导致植被营养不良。

\section{3 基于生态环保理念的生态公路设计}

3.1 路侧设计

实际设计过程, 设计人员需要坚持按照以人为本、安全 为主的原则进行。第一, 对于设计人员, 需要进行标识标线合 理设置, 确保汽车行车路线得到具体明确, 避免汽车放线偏 离发生路侧事故。第二, 规划人员需要进行路测净区设置, 使其留有相应区域提供休息, 同时还应进行路测净区生态绿 化设计。当设计路测净区时, 设计人员需要按照公路路面情 况进行, 确保公路安全性。第三, 对路测护栏进行设计时, 因 为公路路面不适合设置路侧净区, 所以, 此路段应该增加路 测护栏, 在进行护栏选择时, 需要结合当地生态状况进行。第 四, 设计人员还应重点注意路侧边沟设计, 在生态环保理念 的基础上, 其路侧边沟主要是以暗藏式边沟为主, 确保路面 水得到有效疏导。

\section{2 路基设计}

在对生态公路进行路基设计时, 规划人员应先对以下内 容予以特别注意: 第一, 填方边坡率的明确, 设计人员需要对 
现场填土情况进行了解, 以便于进行坡率计算与规划。第二, 设计人员应该结合问题产生原因, 深入研究路基施工周边环 境, 确保环境要素的正确了解, 例如: 地形地貌在施工方面的 影响等。第三, 设计过程规划人员需要提升自身安全意识, 坚持按照相关设计原则进行。

路基规划时, 设计人员还应按照不同条件展开规划工作, 在对路基填土实际高度进行明确时, 应以此为基础展开路基 设计工作, 即多数路段填土高度低于 $3 \mathrm{~m}$, 边坡率 $1: 4$; 如果超 过 $3 \mathrm{~m}$, 边坡率应以 $1: 2$ 为准, 在对边坡率进行相应调整后, 以 满足路面实际要求。针对不同环境要素, 边坡率需要控制 $1: 0.75 \sim 1: 1$ 间。若要减少周边生态可能在栖息生物造成影 响, 在对公路路堤进行规划时, 应将其高度控制 $2 \mathrm{~m}$ 以下, 如 果情况比较特殊, 路堤高度应超过 $3 \mathrm{~m}$ 标准。另外, 当设计人 员设计路基取土时, 同样需要按照就地取材的原则进行, 尽 可能将废弃物放置相应区域, 并对部分成熟、直径 $10 \mathrm{~cm}$ 以上 树木予以移植, 达到环境保护效果。

\section{3 绿化设计}

当进行绿化设计时, 设计人员需要结合 “露透封” 理念 进行, 以便于扩大公路绿化面积, 在对生态景观予以彰显的 同时, 使公路整体美感得到显著提升, 进而提高行车人员舒 适度。对于设计人员来讲, 公路绿化设计主要从两方面进行 加强: 第一, 中央隔离带, 绿化目的为避免车辆间发生炫目情 况, 并进行路面美化, 在进行实际设计时, 需要按照当地气候 进行植被选择, 通常是以耐旱性、抗污染性较强植被为主, 在实现生态环境平衡的同时, 确保车辆的行车安全。第二, 景观休息, 对此区域设计时, 需要盡量选择景观优美位置, 使 其和当地生态呈现和谐发展现状, 并实现人文景观、自然景 观间的协调发展。

\section{4 生态公路问题现状的解决措施}

4.1 合理规划道路

城市的发展必须经历从小到大的过程, 在这个过程中, 很多城市并没有事先规划好道路问题, 所以堵车已经成为一 种常态。针对这一现实, 全球变暖和城市化要求越来越高, 因此生态公路设计和建设更加困难。由于城市道路不能重新 规划, 内在的生态环境不可能发生变化, 所以在保护原生态 环境的前提下, 我们可以充分挖掘道路边缘, 尽可能扩大土 地利用范围。就不能重新规划的道路而言, 一些城市正在规 划一个新的区域, 而且这将是必要的。在合理规划道路建设
之前, 让城市继续发展, 生态环境也不会被破坏。

4.2 按照因地制宜原则

在进行生态公路设计时, 应该对其进行多方面分析, 主 要是围绕 “因地制宜” 原则进行, 其主要是指：按照地方天 气和水源等进行, 当进行公路建设时, 应以维持原有生态为 主, 实现生态面积的扩大。设计人员只有按照因地制宜原则, 对其影响因素进行综合分析, 才能更好引入适宜本地树种、 草种, , 确保草种的合理选配, 使其存活率得到显著提升。与 此同时, 设计人员还应对树种应用范围进行考虑, 若是充当 公路隔离带, 需要以低矮灌木为主, 以便于开阔行人和司机 视野。在对道路两侧进行绿化景观设计时, 应该将高大树种 作为重点, 以便于向行人、行车人员提供乘凉处, 降低事故发 生。

\section{3 多元化的设计}

生态道路设计的多样化包括道路设计的多样化和生态 要素的多元化设计。道路设计的多样化是指从现实和现实的 道路合理化。在此前提下, 更多的创造性因素被纳入道路建 设以及车道中。尽可能设计以确保实用性, 并确保美观。生 态要素的多元化范围很广。除了树种的多样性之外, 路旁的 自然生态也非常重要。花坛, 草坪, 喷泉, 立交桥, 人行道, 街 口等。所以当设计师们进行规划和设计时, 他们必须尽可能 地具有想象力和多样性。在特定时间, 迎合时间, 迎合大众喜 好, 并显示不同的城市。为了创造一个美好而美丽的城市风 格而不解努力。

\section{5 结语}

现阶段, 由于我国对于生态公路的研究尚不成熟, 因此 在设计和建设过程中也出现了不少问题, 但推动基于生态环 保理念的生态公路建设势在必行。因此, 我国相关领导部门 应提高对生态公路的重视程度, 增大人力物力投资力度, 积 极借鉴国外成熟经验, 引进先进技术, 从而推动我国生态公 路的可持续发展。

\section{[参考文献]}

[1]董亮亮.基于环保理念的生态公路设计研究[J]. 黑龙 江科技信息,2017,(9):57+59.

[2]吴琼.基于环保理念的生态公路设计[J].交通世界(工 程技术),2015,(6):38+39。

[3]赵友平,童云深.山区高速公路生态环境保护技术对 策及措施[J].中外公路,2014,34(5):13-18. 